\title{
Agreement Between Self-Reported Information and Administrative Data on Comorbidities, Imaging and Treatment in Denmark - A Validation Study of 38,745 Patients with Knee or Hip Osteoarthritis
}

\author{
Halit Selçuk (iD) \\ Ewa M Roos (D) ${ }^{2}$ \\ Dorte T Grønne ${ }^{2}$ \\ Martin T Ernst ${ }^{3}$ \\ Søren T Skou (iD) 2,4 \\ 'Department of Physiotherapy and \\ Rehabilitation, Marmara University, \\ İstanbul, Turkey; ${ }^{2}$ Research Unit for \\ Musculoskeletal Function and \\ Physiotherapy, Department of Sports \\ Science and Clinical Biomechanics, \\ University of Southern Denmark, \\ Odense, Denmark; ${ }^{3}$ Clinical \\ Pharmacology, Pharmacy and \\ Environmental Medicine, Department of \\ Public Health, University of Southern \\ Denmark, Odense, Denmark; ${ }^{4}$ The \\ Research Unit PROgrez, Department of \\ Physiotherapy and Occupational Therapy, \\ Naestved-Slagelse-Ringsted Hospitals, \\ Slagelse, Denmark
}

Purpose: To validate self-reported information obtained from patients with knee or hip osteoarthritis $(\mathrm{OA})$ in primary care against administrative data from the three national Danish registries.

Patients and Methods: We compared the baseline and 12-month follow-up data from 38,745 patients with knee or hip OA participating in the Good Life with osteoArthritis in Denmark (GLA: $\mathrm{D}^{\circledR}$ ) program with registry-based data on joint surgeries, pain medication dispensing, radiographs, and hospital diagnoses. Agreement was calculated using Cohen's Kappa (k) and percentage agreement, both with 95\% CI.

Results: There was a moderate agreement between self-report and registry-based data for previous knee surgery $(\mathrm{k}=0.58,84.99 \%)$ and a substantial agreement for previous hip surgery $(\mathrm{k}=0.73,97.05 \%)$. Agreement varied from 0.05 to 0.95 and $84.99 \%$ to $99.94 \%$ for different types of surgeries with lowest agreement for collateral ligament surgery $(\mathrm{k}=0.05,99.82 \%)$ and highest agreement for joint replacement $(\mathrm{k}=0.95,99.54 \%$ for $\mathrm{knee}$; $\mathrm{k}=0.95,99.48 \%$ for hip). There was a moderate agreement $(\mathrm{k}=0.41,81.59 \%)$ for knee and a slight agreement $(\mathrm{k}=0.20,64.79 \%)$ for hip radiographs. Agreement varied from 0.01 to 0.53 and $65.39 \%$ to $99.90 \%$ for pain medication with lowest agreement for topical NSAID $(\mathrm{k}=0.01,95.00 \%)$ and highest agreement for opioids $(\mathrm{k}=0.53,92.56 \%)$. For comorbidities, agreement varied from 0.14 to 0.90 and $78.07 \%$ to $98.91 \%$, with lowest agreement for anemia or other blood disease $(\mathrm{k}=0.14,97.63 \%)$ and highest agreement for diabetes $(\mathrm{k}=0.90,98.73 \%)$.

Conclusion: As the most common types of pain medication used by patients with OA can be bought over-the-counter and as most OA patients are treated in primary care, which is often not covered by national registries, self-report of pain medication use and comorbidities is preferred but cannot be sufficiently validated against registry-based data. Future studies collecting self-reported information on joint surgery and pain medication from patients with OA should use a less detailed categorization to improve accuracy.

Keywords: self-report, data validity, osteoarthritis, Denmark

\section{Introduction}

In research and in clinical practice, self-reported information on the medical history of the patient is often preferred over medical records or registry-based data because it is more accessible and associated with lower cost. ${ }^{1,2}$ However, self-reported information may be affected by recall bias and social desirability bias, ${ }^{1}$ and the accuracy of the answers can also be influenced by the design of the
Correspondence: Søren T Skou Research Unit for Musculoskeletal Function and Physiotherapy, Department of Sports Science and Clinical Biomechanics, University of Southern Denmark, 55 Campusvej, Odense, DK-5230, Denmark Tel +4523708640

Email stskou@health.sdu.dk 
specific questionnaire and the specificity of the questions. ${ }^{3}$ Haapanen et al showed that diabetes, hypertension, coronary heart disease and general cardiovascular diseases reported by the participants were highly compatible with what was reported in medical records. On the contrary, the information taken from the participants about musculoskeletal problems, eg low back problems, knee and hip osteoarthritis (OA), was incompatible with the information in medical records. ${ }^{4}$

$\mathrm{OA}$ is a degenerative joint condition that causes joint pain, functional problems, reduced quality of life, and it is one of the leading causes of pain and disability globally. Since accurate information on the medical history (eg comorbidities, medication, and previous surgery) is important for decisions on the treatment of $\mathrm{OA}^{5,6}$ it is important to determine the accuracy of self-reported information obtained from patients with OA. To evaluate the accuracy of self-reported information in different conditions, previous studies have compared the self-reported information with medical records, ${ }^{4,7-10}$ administrative databases $^{11-14}$ or clinical examinations. ${ }^{15,16}$ Although none of these methods can be considered as the gold standard, administrative databases covering large populations, available at all times and with a high level of completeness and validity can be considered as one of the most useful and accurate ways of validating selfreported information. ${ }^{17,18}$ To our knowledge, there are no previous studies which investigate the agreement between commonly used self-reported information obtained from patients with $\mathrm{OA}$ and registry-based data with national coverage.

Good Life with osteoArthritis in Denmark (GLA:D) is a nationwide program that aims to implement treatment guidelines for knee and hip OA in clinical practice using self-reported and objectively measured information. ${ }^{19}$ The aim of our study was to examine the agreement between self-reported information (comorbidities, radiographs, knee and hip surgery, prescription-based pain medication) obtained from patients with knee or hip OA participating in GLA:D and data obtained from the nationwide Danish registries.

\section{Materials and Methods Design}

This was a registry-based study using baseline and follow-up data from 38,745 patients with symptoms and/or functional limitations of the knee or hip OA participating in GLA:D with data from the Danish national registries. ${ }^{19}$ This study was reported according to recommendations of the STROBE statement for reporting observational studies. ${ }^{20}$

\section{Ethics and Permissions}

According to the North Denmark Region, Local Ethics Committee, ethical approval was not needed for GLA:D program. The Danish Data Protection Agency at SDU has approved the GLA:D registry (approval no.: SDU; 10.084) and the current analyses (approval no.: SDU; 10.124). According to the Danish Data Protection Act, patient consent was not required as personal data was processed only for research and statistical purposes. This study was approved by Statistics Denmark's Scientific Board.

\section{Participants}

GLA:D consists of 2 sessions of patient education and 12 supervised, group-based exercise sessions led by a physiotherapist over an 8-week period. Participants referred to GLA:D from the initiation of the program in January 2013 until the end of December 2018 were included in this study. There are 3 ways for a patient with OA to get referred to GLA:D in Denmark: 1) by their general practitioner, 2) by themselves or 3) by an orthopedic surgeon. Participants were evaluated for eligibility by the treating physiotherapist. Participants understanding Danish with symptoms and/or functional limitations of knee or hip OA were eligible if they did not have any other reasons for their joint symptoms than OA (eg inflammatory joint disease or patellar tendinopathy) or other symptoms that were more prominent than their OA symptoms (ie pain in other body regions). According to Danish ${ }^{21}$ and international guidelines; ${ }^{5}$ radiographs are not needed to diagnose $\mathrm{OA},{ }^{5}$ and therefore not part of the eligibility criteria for GLA:D. Patient characteristics, details of the GLA:D treatment program and outcomes have previously been published. ${ }^{19}$

\section{Variables \\ Self-Reported Information by Patients}

All the self-reported data were available from the GLA:D registry. Self-reported data was collected from patients through online questionnaires distributed via email. Education and pain intensity (reported on a $0-100$ visual analogue scale (VAS) as average pain during the previous month) as well as comorbid diseases (collected from 01.07.2014, category of diabetes was divided into Diabetes type 1 and Diabetes type 2 after 26.08.2018 and 
high cholesterol was only collected from 24.10.2018) were reported by the patients at the baseline evaluation. The comorbid diseases were divided into 14 categories and patients reported the presence of each condition as yes or no. At baseline and at 12 months follow-up, patients selfreported whether they underwent hip replacement surgery (yes/no) and knee replacement surgery (yes/no) prior to GLA:D or during the 12 months follow-up, respectively.

\section{Self-Reported Information Collected by Physiotherapist}

Information on age and gender was extracted from the personal identification number, unique to each person living in Denmark (CPR number). Whether or not a radiograph was taken (no, yes, more than 6 months ago, yes, within the last 6 months, do not know) was questioned by the treating physiotherapist at the baseline evaluation, while BMI was calculated from height and weight entered by the physiotherapist. Information about previous surgery for the right/left knee and hip joints (yes/ no) was questioned at baseline evaluation (collected from 13.05.2016). If the patient reported having previous surgery on either hip or knee, the type of surgery was also obtained for that specific joint. Patients reported the type of surgery from a list of 15 surgery subgroups for knee and 13 surgery subgroups for hip. Pain medication type was obtained from the patients by the treating physiotherapist at the baseline evaluation. Examples of the different medications were given in the GLA:D data collection. Patients reported the use of medication within the last three months from a list of 12 medication categories.

Patients and physiotherapists type in their response to questions directly in the online GLA: $\mathrm{D}^{\circledR}$ registry system. No paper forms are used. The database manager routinely performs a data validation procedure checking continuous variables for extreme values and categorical variables for unexpected distributions. In case of deviations error detections are performed.

\section{National Data Sources}

Three national data sources were used to examine the agreement between self-report and registries: the National Patient Registry, ${ }^{22}$ the National Prescription Registry, ${ }^{23}$ and the Danish Civil Registration System. ${ }^{24}$ The CPR number, assigned to all Danish residents, was used to link all data sources. ${ }^{24}$ The Danish National Patient Registry (DNPR) contains nationwide data on all inpatient admissions since 1978 and outpatient and emergency room contacts since 1995. Also, since 2003 it covers private hospitals as well as private specialty clinics except private practice specialists and general practitioners (GP). Treatments (surgery and other treatments) and examinations (radiological and other examinations) are registered by the physician after the completion of procedure. Surgical operations are coded according to the Nordic Medico-Statistical Committee (NOMESCO). For each patient contact, one primary (main reason for the hospital contact) and relevant secondary discharge diagnoses have been coded according to the International Classification of Diseases Revision 8 (ICD-8) from 1977 to 1993 and International Classification of Diseases Revision 10 (ICD-10) since 1994 by discharging physicians at the time of hospital discharge. ${ }^{25}$ The registry automatically checks for possible errors and discrepancies and sends them back to hospital systems for correction. ${ }^{22,25}$ The DNPR gives valuable and specific information on diagnoses, treatments, and examinations of patients. ${ }^{22,25}$ Previous studies have shown that DNPR is valid for reporting comorbidities, ${ }^{26}$ previous orthopedic surgery, ${ }^{25}$ diagnostic procedures,${ }^{27}$ prescription-based medications ${ }^{23}$ and in-hospital medical treatments. ${ }^{25}$

The Danish National Prescription Registry contains data on all prescription drugs since 1995. Type of drug, date of dispensing, and quantity are included in the data. The Anatomic Therapeutic Chemical (ATC) index is used to categorize the drugs. Since the data on Danish National Prescription Registry constitute a key component of selling prescription drugs in pharmacies, inter/intraobserver information bias are very unlikely to occur in prescription registry. ${ }^{23}$

The Danish Civil Registration System allows linkage between registries, extraction of population controls, and tracking of Danish citizens. High data quality in the Danish Civil Registration System is ensured by law and several processes, such as ongoing validation and error correction of the recorded information. ${ }^{24}$

\section{Data Analysis}

Two researchers extracted and uploaded the data from the GLA:D registry to a secure server environment at The Danish Health Data Authority. Afterwards GLA:D data was linked to the national Danish registries on the server via the CPR number. The rules of construction of the CPR numbers were implemented in the GLA:D data collection and only valid CPR numbers were allowed to be entered. The combined dataset on the server was analyzed by one 
researcher. For comparability of the GLA:D and registrybased data, GLA:D registry data were translated into ATC Classification System codes for prescription drugs, International Statistical Classification of Diseases and Related Health Problems (ICD-10) codes for comorbidities and web-based Health Care Classification (SKS) system codes for non- and surgical hospital procedures. Algorithms that combine ICD codes with prescription codes increase the probability of identifying comorbidities in DNPR, ${ }^{25}$ therefore, we also used ATC codes in addition to ICD codes to increase the probability of identifying registry-based comorbidities. Details of variables and adaptation of the data from GLA:D registry to fit the available data from Danish registries for comparability are presented in Appendix 1. ATC codes were extracted from the National Prescription Registry if the patient had a prescribed medication purchase 3 months prior to index date. SKS codes before index date and, SKS codes between the index date and the date of reporting the 12 months follow-up data were extracted from DNPR for each patient. Radiographs prior to index date were extracted from DNPR for the most affected joint. If the side of radiograph was not available in the DNPR, the patient was excluded from the analysis. Comorbidities were defined as having a relevant diagnosis within 5 years prior to index date or redeeming a prescription medication within 1 year prior to index date. Missing datapoints in GLA:D were also set to be missing in the corresponding registry variable. Details of the ICD-10, SKS and ATC codes are presented in Appendix 2. Then, we evaluated the agreement between the GLA:D data and registry-based data.

We calculated the standard statistics of Cohen's kappa and percentage agreement (ie how many yes and no in GLA:D that correspond to yes and no in the national registries, respectively), with $95 \%$ confidence intervals where appropriate. Kappa values $<0$ interpreted as no agreement, $0.00-0.20$ as slight, $0.21-0.40$ as fair, $0.41-$ 0.60 as moderate, $0.61-0.80$ as substantial, and $0.81-1.00$ as almost perfect agreement. ${ }^{28}$ All data analysis was conducted using Stata 16.1. ${ }^{29}$

\section{Results}

Of 38.745 participants, 27,669 (71\%) were female. The mean age of the participants was $65( \pm 9.88)$ years. The characteristics of the participants are described in Table 1.

There was a perfect agreement between self-report and registry-based data for baseline joint replacement surgery,
Table I Characteristics of the Study Participants

\begin{tabular}{|c|c|}
\hline Participant Characteristics & $n=38,745$ \\
\hline Age, mean (SD) & $65( \pm 9.88)$ \\
\hline \multicolumn{2}{|l|}{ Gender, N (\%) } \\
\hline Female & 27,669 (7I\%) \\
\hline Male & II,076 (29\%) \\
\hline \multicolumn{2}{|l|}{ Education, $\mathbf{N}(\%)$} \\
\hline Primary school & $6062(16 \%)$ \\
\hline Secondary school & $3743(9.7 \%)$ \\
\hline $\begin{array}{l}\text { Short-term education ( }<3 \text { years after secondary } \\
\text { school) }\end{array}$ & $6656(17 \%)$ \\
\hline $\begin{array}{l}\text { Middle-term education (3-4 years after secondary } \\
\text { school) }\end{array}$ & $|3,33|(34 \%)$ \\
\hline $\begin{array}{l}\text { Long-term education ( } \geq 5 \text { years after secondary } \\
\text { school) }\end{array}$ & $3830(9.9 \%)$ \\
\hline \multicolumn{2}{|l|}{ BMI $\left(\mathrm{kg} / \mathrm{m}^{2}\right), \mathbf{N}(\%)$} \\
\hline Less than 18.5 & $180(0.5 \%)$ \\
\hline $18.5-24.9$ & $10,563(27 \%)$ \\
\hline $25.0-29.9$ & $15,254(39 \%)$ \\
\hline 30.0 or more & $12,6 \mid 3(33 \%)$ \\
\hline Pain Intensity (VAS, 0-100), mean (SD) & $47.6( \pm 22.0)$ \\
\hline \multicolumn{2}{|l|}{ Pain Medication, N (\%) } \\
\hline Yes & $24,983(64 \%)$ \\
\hline No & $13,762(36 \%)$ \\
\hline
\end{tabular}

Abbreviations: BMI, Body Mass Index (data missing on 138 (0.4\%)); VAS, visual analogue scale (data missing on 5123 (13.2\%)); data missing on 8 (0.02\%) for pain medication; SD, standard deviation.

with a kappa value of $0.95(95 \% \mathrm{CI}=0.94-0.96)$ and agreement of $99.54 \%(95 \% \mathrm{CI}=99.46-99.61)$ for knee and a kappa value of $0.95(95 \% \mathrm{CI}=0.94-0.96)$ and agreement of $99.48 \%(95 \% \mathrm{CI}=99.40-99.55)$ for hip (Table 2). There was a perfect agreement between selfreport and registry-based data for baseline to 12-month follow-up joint replacement surgery, with a kappa value of $0.91(95 \% \mathrm{CI}=0.89-0.92)$ and agreement of $99.15 \%$ (95\% CI=98.99-99.28) for knee and a kappa value of 0.94 $(95 \% \mathrm{CI}=0.92-0.96)$ and agreement of $99.45 \%(95 \% \mathrm{CI}=$ 99.32-99.56) for hip (Table 2).

The agreement between self-report and registry-based data for the type of prior surgery of the knee and hip joints collected by the physiotherapist is presented in Table 3 . There was a moderate agreement between self-report and registry-based data for previous knee surgery (kappa: 0.58, agreement: $84.99 \%$ ) and a substantial agreement for previous hip surgery (kappa: 0.73, agreement: 97.05\%). For previous knee surgery subgroups, kappa values ranged between 0.05 and 0.95 and agreement ranged between 
Table 2 Agreement Between Self-Report and Registry-Based Data for Baseline and Baseline to I2-Month Follow-Up Replacement Surgery

\begin{tabular}{|l|l|l|l|l|}
\hline Self-Reported Information & $\begin{array}{l}\text { GLA:D }^{\circledR} \\
\text { Registry (n) }\end{array}$ & $\begin{array}{l}\text { National } \\
\text { Registries (n) }\end{array}$ & Agreement (95\% Cl) & Kappa (95\% Cl) \\
\hline $\begin{array}{l}\text { Replacement surgery prior to GLA:D } \\
\text { Knee replacement surgery } \\
\text { Yes } \\
\text { No }\end{array}$ & $\begin{array}{l}1600 \\
31,989\end{array}$ & $\begin{array}{l}1617 \\
31,972\end{array}$ & 99.54\% (99.46-99.6I) & $0.95(0.94-0.96)$ \\
\hline $\begin{array}{l}\text { Hip replacement surgery } \\
\text { Yes } \\
\text { No }\end{array}$ & $\begin{array}{l}1910 \\
31,679\end{array}$ & $\begin{array}{l}1917 \\
31,672\end{array}$ & $99.48 \%(99.40-99.55)$ & $0.95(0.94-0.96)$ \\
\hline $\begin{array}{l}\text { Baseline to I2-month follow-up } \\
\text { replacement surgery } \\
\text { Knee replacement surgery } \\
\text { Yes } \\
\text { No }\end{array}$ & $\begin{array}{l}765 \\
15,193\end{array}$ & $\begin{array}{l}771 \\
15,187\end{array}$ & $99.15 \%(98.99-99.28)$ & $0.91(0.89-0.92)$ \\
\hline $\begin{array}{l}\text { Hip replacement surgery } \\
\text { Yes } \\
\text { No }\end{array}$ & $\begin{array}{l}760 \\
15,198\end{array}$ & $\begin{array}{l}776 \\
15,182\end{array}$ & $99.45 \%(99.32-99.56)$ & $0.94(0.92-0.96)$ \\
\hline
\end{tabular}

Notes: Data missing on 5156 (13.3\%) for knee and hip replacement surgery prior to GLA:D; data missing on I0,309 (26.6\%) for baseline to I2-month follow-up knee and hip replacement surgery.

96.04\% and 99.94\%. The agreement was slight to almost perfect with the lowest agreement for collateral ligament surgery and highest agreement for joint replacement. For previous hip surgery subgroups, kappa values ranged between 0.17 and 0.94 and agreement ranged between $99.50 \%$ and $99.94 \%$. The agreement was slight to almost perfect with the lowest agreement for other surgeries and the highest agreement for joint replacement.

The agreement between self-report and registry-based data for different types of pain medication is presented in Table 4. Kappa values ranged between 0.01 and 0.53 and agreement ranged between $65.39 \%$ and $99.90 \%$. The agreement was slight to moderate with the lowest agreement for topical NSAID and highest agreement for opioids. There was a moderate agreement (kappa: 0.41, agreement: $81.59 \%$ ) for knee radiographs and a slight agreement (kappa: 0.20, agreement: $64.79 \%$ ) for hip radiographs (Table 4).

The agreement between self-report and registry-based data for comorbidities is presented in Table 5. Kappa values ranged between $0.14(95 \% \mathrm{CI}=0.13-0.15)$ to $0.90(95 \% \mathrm{CI}=$ $0.89-0.91)$ and agreement ranged between $78.07 \%(95 \% \mathrm{CI}=$ $77.61-78.52)$ to $98.91 \%(95 \% \mathrm{CI}=98.49-99.24)$. The agreement was slight to almost perfect with the lowest agreement for anemia or other blood diseases and the highest agreement for diabetes. The details of the answer distribution in GLA:D data and registry-based data for each variable can be found in Appendix 3.

\section{Discussion}

In this study, we investigated the agreement between selfreported information from the GLA:D registry and registry-based data from national registries. We found a perfect agreement for replacement surgery of knee and hip, moderate agreement for previous knee surgery, and substantial agreement for previous hip surgery between the GLA:D and registry-based data. When categorizing surgeries into subgroups, the agreement level ranged from slight to almost perfect for different types of surgery with a higher agreement when collapsing into less detailed categories of surgery. For medication subgroups, agreement ranged from slight to moderate with the highest agreement on opioids. The agreement also ranged from slight to almost perfect for comorbidities with the highest agreement on diabetes, while the agreement for having had a radiograph was moderate for knee radiographs and only slight for hip radiographs.

\section{Surgery and Imaging}

Surgical procedures have been coded in DNPR according to the Nordic Medico-Statistical Committee (NOMESCO) 
Table 3 Agreement Between Self-Report Collected by Therapist and Registry-Based Data for Previous Surgery of the Knee and Hip Joints

\begin{tabular}{|c|c|c|c|c|}
\hline Surgery & $\begin{array}{l}\text { GLA:D }{ }^{\circledR} \\
\text { Registry (n) }\end{array}$ & $\begin{array}{l}\text { National } \\
\text { Registries (n) }\end{array}$ & Agreement (95\% Cl) & Kappa $(95 \%$ Cl) \\
\hline $\begin{array}{l}\text { Knee surgery } \\
\text { Yes } \\
\text { No }\end{array}$ & $\begin{array}{l}3132 \\
10,247\end{array}$ & $\begin{array}{l}3070 \\
10,309\end{array}$ & $85.02 \%(84.4 I-85.62)$ & $0.58(0.56-0.60)$ \\
\hline $\begin{array}{l}\text { Hip surgery } \\
\text { Yes } \\
\text { No }\end{array}$ & $\begin{array}{l}635 \\
12,744\end{array}$ & $\begin{array}{l}894 \\
12,485\end{array}$ & $97.05 \%(96.75-97.33)$ & $0.73(0.7 \mathrm{I}-0.74)$ \\
\hline $\begin{array}{l}\text { Which surgery? (Knee) Detailed } \\
\text { Arthroscopic surgery }^{\mathrm{a}} \\
\text { ACL reconstruction } \\
\text { PCL reconstruction } \\
\text { Collateral ligaments surgery } \\
\text { Patellae-related surgery } \\
\text { OA surgery } \\
\text { Other }\end{array}$ & $\begin{array}{l}3019 \\
216 \\
23 \\
66 \\
145 \\
648 \\
391\end{array}$ & $\begin{array}{l}2486 \\
131 \\
5 \\
7 \\
46 \\
666 \\
1038\end{array}$ & $\begin{array}{l}96.03 \%(95.83-96.23) \\
99.64 \%(99.58-99.70) \\
99.94 \%(99.91-99.96) \\
99.82 \%(99.77-99.86) \\
99.61 \%(99.54-99.67) \\
99.77 \%(99.72-99.82) \\
96.79 \%(96.61-96.96)\end{array}$ & $\begin{array}{l}0.70(0.69-0.7 I) \\
0.60(0.59-0.6 I) \\
0.21(0.21-0.22) \\
0.05(0.05-0.06) \\
0.20(0.19-0.21) \\
0.93(0.92-0.94) \\
0.12(0.1 I-0.12)\end{array}$ \\
\hline $\begin{array}{l}\text { Less detailed categorization } \\
\text { Arthroscopic surgeries }^{d} \\
\text { Joint replacement }^{\text {e }} \\
\text { Other knee surgeries }^{f}\end{array}$ & $\begin{array}{l}3094 \\
615 \\
611\end{array}$ & $\begin{array}{l}2505 \\
623 \\
1070\end{array}$ & $\begin{array}{l}96.05 \%(95.85-96.24) \\
99.83 \%(99.78-99.87) \\
96.62 \%(96.44-96.80)\end{array}$ & $\begin{array}{l}0.7 I(0.70-0.72) \\
0.95(0.94-0.96) \\
0.21(0.20-0.22)\end{array}$ \\
\hline $\begin{array}{l}\text { Which surgery? (Hip) Detailed } \\
\text { Arthroscopic surgery } \\
\text { OA surgery } \\
\text { Fracture surgery } \\
\text { Otheri }\end{array}$ & $\begin{array}{l}34 \\
712 \\
72 \\
76\end{array}$ & $\begin{array}{l}34 \\
748 \\
73 \\
88\end{array}$ & $\begin{array}{l}99.94 \%(99.91-99.96) \\
99.78 \%(99.73-99.82) \\
99.83 \%(99.78-99.87) \\
99.65 \%(99.58-99.71)\end{array}$ & $\begin{array}{l}0.68(0.67-0.69) \\
0.94(0.93-0.95) \\
0.54(0.53-0.55) \\
0.17(0.16-0.18)\end{array}$ \\
\hline $\begin{array}{l}\text { Less detailed categorization } \\
\text { Arthroscopic surgeries }{ }^{g} \\
\text { Joint replacement } \\
\text { Other hip surgeries }\end{array}$ & $\begin{array}{l}34 \\
710 \\
150\end{array}$ & $\begin{array}{l}34 \\
745 \\
163\end{array}$ & $\begin{array}{l}99.94 \%(99.91-99.96) \\
99.79 \%(99.73-99.83) \\
99.50 \%(99.42-99.56)\end{array}$ & $\begin{array}{l}0.68(0.67-0.69) \\
0.94(0.93-0.95) \\
0.37(0.36-0.38)\end{array}$ \\
\hline
\end{tabular}

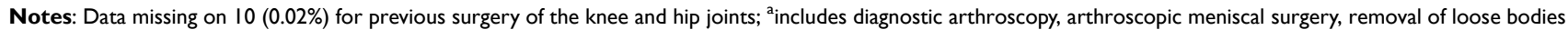
in knee joint, debridement, microfracture and partial synovectomy surgeries; 'bincludes surgery for jumper's knee, patella stabilization and other surgeries for patella; ${ }^{c}$ includes replacement and osteotomy surgeries; ${ }^{d}$ includes diagnostic arthroscopy, arthroscopic meniscal surgery, removal of loose bodies in knee joint, debridement, microfracture, partial synovectomy, $\mathrm{ACL}$ and $\mathrm{PCL}$ reconstruction surgeries; ${ }^{\mathrm{t}}$ the information on previous surgery in Table 3 have been collected from patients by physiotherapist after 13.05.2016 but information on replacement surgery in Table 2 have been reported directly by patients from the start of GLA:D ${ }^{\circledR}$ (29.0I.20I3). This is the reason for the discrepancies in the results; includes collateral ligaments surgery, surgery for jumper's knee, patella stabilization, other surgeries for patella, osteotomy

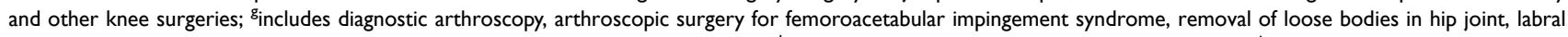

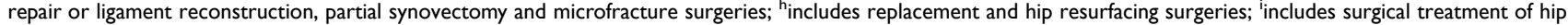
dysplasia, tenotomy and other hip surgeries; 'includes surgical treatment of hip dysplasia, tenotomy, hip resurfacing, fracture surgery and other hip surgeries.

system since $19966^{30}$ Previous studies have shown that data on surgical procedures in DNPR is valid. ${ }^{31-33}$ The results of this study indicate that there is almost perfect agreement between GLA:D and registry-based data on the knee and hip replacement surgery at baseline and followup. These findings are consistent with previous studies that found substantial to almost perfect agreement between self-report and administrative data. ${ }^{10,34}$

For different types of surgery, the agreement varied substantially between types but increased when collapsed into less detailed categories of surgery. Besides potential misclassifications in DNPR, this indicates difficulty in discriminating between detailed surgery types for the patients and suggests that less detailed categories should be used when asking patients to self-report prior surgery. Also, the high agreement on joint replacement compared to other types of surgery might be due to the fact that it is easier to recall major operation that is mostly performed later in life compared to other surgery types like arthroscopy. 
Table 4 Agreement Between Self-Report and Registry-Based Data for Different Types of Pain Medication and Radiograph Data

\begin{tabular}{|c|c|c|c|c|}
\hline Pain Medication & GLA:D ${ }^{\circledR}$ Registry (n) & National Registries (n) & Agreement (95\% Cl) & Kappa $(95 \%$ Cl) \\
\hline Pain medication ${ }^{\mathrm{a}}$ & 24,983 & 17,615 & $66.45 \%(65.97-66.92)$ & $0.35(0.34-0.36)$ \\
\hline Opioids ${ }^{b}$ & 2917 & 3820 & $92.56 \%$ (92.30-92.82) & $0.53(0.52-0.54)$ \\
\hline \multicolumn{5}{|l|}{ Detailed categorization } \\
\hline Paracetamol & 20,955 & 13,122 & $65.39 \%(64.9 \mathrm{I}-65.86)$ & $0.33(0.32-0.33)$ \\
\hline NSAID & 13,437 & 8881 & $74.84 \%$ (74.4I-75.27) & $0.40(0.39-0.4 I)$ \\
\hline Topical NSAID & 1878 & 90 & $95.00 \%(94.78-95.21)$ & $0.01(0.01-0.01)$ \\
\hline Glucosamine & 5087 & 113 & $86.96 \%(86.62-87.29)$ & $0.02(0.02-0.03)$ \\
\hline Hyaluronic acid injection & 29 & 18 & $99.90 \%$ (99.87-99.93) & $0.21(0.20-0.22)$ \\
\hline Corticosteroid injection & 777 & 1378 & $95.85 \%$ (95.64-96.04) & $0.23(0.22-0.24)$ \\
\hline Morphine or other opioids & 1307 & 802 & $96.70 \%(96.52-96.88)$ & $0.38(0.37-0.39)$ \\
\hline Tramadol & 1214 & 2770 & $94.23 \%(93.99-94.46)$ & $0.41(0.40-0.42)$ \\
\hline Codeine & 532 & 500 & $97.89 \%$ (97.75-98.03) & $0.20(0.19-0.21)$ \\
\hline Tricyclic antidepressants & 180 & 2931 & $92.68 \%$ (92.4I-92.94) & $0.08(0.08-0.08)$ \\
\hline Anticonvulsants & 219 & 1242 & $97.07 \%$ (96.90-97.24) & $0.22(0.21-0.22)$ \\
\hline Methotrexate & 150 & 180 & $99.45 \%$ (99.37-99.52) & $0.35(0.34-0.36)$ \\
\hline X-ray of most affected joint & & & $77.18 \%(75.46-76.52)$ & $0.34(0.33-0.35)$ \\
\hline Yes & 21,723 & 17,669 & & \\
\hline No & 3196 & 7250 & & \\
\hline X-ray of most affected knee & 15,923 & $|3,88|$ & $81.59 \%$ (79.48-80.63) & $0.4 \mathrm{I}(0.40-0.43)$ \\
\hline X-ray of most affected hip & 5799 & 3788 & $64.79 \%(63.24-65.57)$ & $0.20(0.18-0.2 I)$ \\
\hline
\end{tabular}

Notes: Data missing on 187 (0.5\%) for X-ray of most affected joint in the GLA:D registry; Data missing on 389 (I.6\%) for X-ray of most affected joint in the Danish National

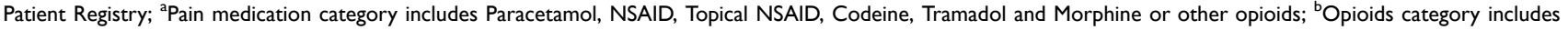
Codeine, Tramadol and Morphine or other opioids.

Since 2002, it has been mandatory for all Danish hospitals to report radiological procedures to the DNPR. ${ }^{35}$ In our study, there was a moderate agreement for the knee and slight agreement for the hip between GLA:D and registry-based data on radiographs with more radiographs reported in GLA:D. Previous studies evaluating the completeness of radiograph registrations in DNPR showed low completeness $(73.1 \%),{ }^{35}$ which question using the DNPR as the gold standard, and may partly explain the lower number of radiographs reported in the national registry compared to self-report in our study. Another potential reason for the overreport of radiograph data in GLA:D compared to registry-based data might be that the radiographs taken in primary care and radiographs taken before 2002 are not recorded in DNPR and also, patients might not know the difference between types of imaging (eg MRI and ultrasound). The reason for the different agreement levels for knee and hip might be that bilateral problems are common, and patients could not accurately recall the joint of which they had a radiograph.

\section{Pain Medication}

The Danish National Prescription Registry contains information by CPR number on all drugs prescribed and dispensed in Danish outpatient pharmacies. ${ }^{36} \mathrm{We}$ found an overreporting for paracetamol and NSAIDs in the GLA:D data compared to the registry-based data, contributing to a fair agreement. This confirms previous findings by Grimaldi-Bensouda et al, who investigated the agreement between physician-reported and patient-reported drugs used for musculoskeletal disorders and showed fair agreement for NSAIDs. ${ }^{37}$ This might be due to the over-the-counter availability of paracetamol and NSAIDs, which are not registered in the national registry. ${ }^{38}$ Also, since the patients in GLA: D were asked about pain medication use, but we retrieved dispensations from the national prescription registry, patients could have had medications in their home that were dispensed at an earlier time point or they could have dispensed medications that they did not use which might lead to a disagreement between the two sources. 
Table 5 Agreement Between Self-Report and Registry-Based Data for Comorbidities

\begin{tabular}{|c|c|c|c|c|}
\hline Comorbidities & GLA:D ${ }^{\circledR}$ Registry (n) & National Registries (n) & Agreement (95\% Cl) & Kappa $(95 \% \mathrm{Cl})$ \\
\hline High blood pressure & & & $87.95 \%(87.59-88.31)$ & $0.75(0.74-0.77)$ \\
\hline Yes & 11,913 & 14,753 & & \\
\hline No & 19,972 & 17,132 & & \\
\hline High cholesterol & & & $84.02 \%(82.04-85.86)$ & $0.63(0.58-0.68)$ \\
\hline Yes & 467 & 441 & & \\
\hline No & 997 & 1023 & & \\
\hline Heart disease & & & $90.95 \%(90.63-91.26)$ & $0.50(0.49-0.52)$ \\
\hline Yes & 2565 & 3880 & & \\
\hline No & 29,319 & 28,004 & & \\
\hline Ulcers or other stomach diseases & & & $78.07 \%(77.61-78.52)$ & $0.20(0.19-0.21)$ \\
\hline Yes & 1678 & 7887 & & \\
\hline No & 30,206 & 23,997 & & \\
\hline Chronic lung disease & & & $92.06 \%(91.76-92.35)$ & $0.52(0.5 \mathrm{I}-0.53)$ \\
\hline Yes & 1986 & 3744 & & \\
\hline No & 29,900 & 28,142 & & \\
\hline Diabetes & & & 98.73\% (98.59-98.86) & $0.90(0.89-0.91)$ \\
\hline Yes & 2030 & 2004 & & \\
\hline No & 26,645 & 26,671 & & \\
\hline Diabetes type I & & & 98.91\% (98.49-99.24) & $0.47(0.44-0.5 \mathrm{I})$ \\
\hline Yes & 37 & 30 & & \\
\hline No & 3177 & 3184 & & \\
\hline Diabetes type 2 & & & $94.52 \%(93.68-95.29)$ & $0.50(0.46-0.53)$ \\
\hline Yes & 251 & 117 & & \\
\hline No & 2963 & 3097 & & \\
\hline Kidney or liver disease & & & $96.98 \%(96.78-97.16)$ & $0.30(0.29-0.31)$ \\
\hline Yes & 435 & 975 & & \\
\hline No & 31,452 & 30,912 & & \\
\hline Anemia or other blood disease & & & $97.63 \%(97.46-97.80)$ & $0.14(0.13-0.15)$ \\
\hline Yes & 382 & 505 & & \\
\hline No & 31,502 & 31,379 & & \\
\hline Cancer & & & $93.80 \%(93.53-94.06)$ & $0.37(0.36-0.38)$ \\
\hline Yes & 878 & 2372 & & \\
\hline No & 31,006 & 29,512 & & \\
\hline Depression & & & $92.20 \%(91.90-92.50)$ & $0.42(0.4 I-0.43)$ \\
\hline Yes & 1406 & 3190 & & \\
\hline No & 30,478 & 28,694 & & \\
\hline Rheumatoid arthritis & & & $95.39 \%(95.15-95.62)$ & $0.24(0.23-0.25)$ \\
\hline Yes & 1590 & 373 & & \\
\hline No & 30,272 & 31,489 & & \\
\hline Neurological disease & & & $86.39 \%(86.01-86.76)$ & $0.18(0.17-0.19)$ \\
\hline Yes & 1698 & 4039 & & \\
\hline No & 30,183 & 27,842 & & \\
\hline
\end{tabular}

Notes: Data missing on 5103 (13.2\%) for high blood pressure, heart disease, ulcers or other stomach diseases, anemia or other blood disease, cancer, and depression; 313 (17.6\%) for high cholesterol; 5 IOI (13.2\%) for chronic lung disease; 44 II (13.3\%) for diabetes; 663 (I7.6\%) for diabetes type I and diabetes type 2; 5100 (I3.2\%) for kidney or liver disease; 5125 (13.2\%) for rheumatoid arthritis; 5106 (13.2\%) for neurological disease in the GLA:D registry. 
Similar to our results, a previous study on the Danish population also showed a moderate agreement between selfreported and registry-based data for opioid use. ${ }^{39}$ Opioids are normally used in OA treatment when needed and not on a day-to-day basis, which might be part of the explanation for the underreporting of opioids in GLA:D, as it can be difficult to report medications that are not used regularly. ${ }^{40}$

There was a fair agreement for hyaluronic acid injection and corticosteroid injection. Since another limitation of the registry-based data is sensitivity towards prescriptions issued by private-practicing specialists, ${ }^{38}$ this might explain the rather low agreement.

\section{Comorbidities}

We found almost perfect agreement for Diabetes, but the agreement was moderate when this category was divided into Diabetes type 1 and Diabetes type 2 from 26.08.2018 and onwards. Some patients might not be able to discriminate between the two types of diabetes and therefore the agreement was lower when asked about diabetes type rather than diabetes in general. Also, this might be due to the ICD code definition, as the category of Diabetes is covered by codes E10 to E14, while Diabetes type 1 is only defined by E10 Diabetes type 2 by E11. Therefore, codes E12 to E14 are ignored when divided into Diabetes type 1 and Diabetes type 2 . There was also a substantial agreement for high blood pressure, high cholesterol and moderate agreement for heart disease. Similar to these results, previous studies have also demonstrated substantial agreement for diabetes between self-report and medical record data and also a moderate to substantial agreement for cardiovascular problems. ${ }^{41,42}$

There was a fair agreement for cancer. The rather low agreement on cancer might be partly explained by the fact that patients in GLA:D are asked about current conditions, while the DNPR would also include cancer that the patients have had within past 5 years, ie, patients in GLA:D do not report the previous cancer cases for which they have been cured. We also found a fair agreement for rheumatoid arthritis (RA), explained by a higher prevalence according to the self-reported information. A potential reason for the higher numbers in GLA:D might be due to the low validity of the DNPR for detecting RA, which has been shown in previous studies, ${ }^{43}$ but also due to misreporting in GLA:D, as the number of cases with rheumatoid arthritis dropped significantly after the label added that rheumatoid arthritis is not the same as OA on 10.07.2015.
For other conditions, the agreement varied from slight to moderate. There was a moderate agreement for chronic lung disease and depression, a fair agreement for kidney or liver disease and a slight agreement for ulcers or other stomach disease, neurological disease and anemia or other blood diseases between GLA:D and registry-based data.

Similar to these results, a study by Koller et al investigated the agreement between self-report and medical record data on comorbidities among 3821 residents of three regions from Alaska, United States of America with a population survey and showed slight to substantial agreement. The agreement was highest for diabetes and cancer, on the contrary, the agreement was lowest for chronic obstructive pulmonary disease (COPD), kidney, and heart disease. Also, the agreement levels differed by age, as the kappa values were lower in adults 65 years or older. ${ }^{44}$ Other studies also found low agreement between self-report and administrative data on the number of comorbidities in adults older than 45 years ${ }^{45}$ and elderly patients at emergency visits. ${ }^{46}$ The mean age of the population in this study was 65 years, and therefore agreement between self-reported and registry-based data on comorbidities might also be affected by age. Consequently, this study demonstrated a slight to almost perfect agreement for different comorbidities, which is consistent with the previous studies.

We recommend that future studies should focus on factors affecting the validity of self-reported information obtained from patients with knee or hip OA.

\section{Strengths and Limitations}

The main strength of this study is the large sample size and coverage of different aspects of medical history. This study also has some limitations. First, even though DNPR has been shown to be valid in previous studies, it also has some limitations as discussed above. Secondly, missing data in the national registries might be a limitation of this study. ${ }^{25}$ Thirdly, we investigated the agreement in the Danish population and therefore these results might not apply to different cultures or countries. Fourthly, since we only had self-reported information on x-ray findings in GLA:D, we were not able to evaluate the radiographic severity of the patient's OA or determine whether they in fact had an x-ray or another type of imaging of their joint. Lastly, GLA:D ${ }^{\circledR}$ information was collected by 923 physiotherapists, and this could contribute to variations in data collection. On the other hand, since all physiotherapists were specifically trained in the GLA: $\mathrm{D}^{\circledR}$ data collection 
and treatment procedures, this could be considered a strength as it is real-world clinical data resembling everyday clinical practice.

\section{Conclusion}

As the most common types of pain medication used by patients with OA can be bought over-the-counter and as most OA patients are treated in primary care, which is often not covered by national registries, self-report of pain medication use, and comorbidities is preferred but cannot be sufficiently validated against registry-based data. Future studies collecting self-reported information on joint surgery and pain medication from patients with OA should use a less detailed categorization to improve accuracy.

\section{Acknowledgments}

The authors would like to acknowledge all the participants and physiotherapists who have engaged in the GLA:D program and provided data for this study. Furthermore, Jacob Harbo Andersen is acknowledged for assisting in data management and analysis.

\section{Funding}

Dr. Skou is currently funded by a grant from Region Zealand (Exercise First) and a grant from the European Research Council (ERC) under the European Union's Horizon 2020 research and innovation program (grant agreement No 801790).

\section{Disclosure}

Dr. Roos and Dr. Skou are the developers of the Good Life with osteoArthritis in Denmark (GLA:D) program, a notfor-profit initiative to implement clinical guidelines in primary care. Professor Ewa M. Roos reports I am deputy editor of Osteoarthritis and Cartilage, the developer of Knee injury and Osteoarthritis Outcome Score (KOOS) and several other freely available patient-reported outcome measures and co-founder of the Good Life with Osteoarthritis in Denmark (GLA:D), a not-for profit initiative to implement clinical guidelines in primary care. Professor Soren T. Skou report grants from the Danish Physiotherapy Association's fund for research, education and practice development, the Danish Rheumatism Association, and the Physiotherapy Practice Foundation, during the conduct of the study; and I am the co-developer of the Good Life with osteoArthritis in Denmark (GLA:D) program (where some of the data for the study is from), a not-for profit initiative to implement clinical guidelines in primary care. The authors report no other conflicts of interest related to this study.

The abstract of this paper was presented at the 2021 OARSI Virtual World Congress as a poster presentation with interim findings. The poster's abstract was published in Volume 29, Supplement 1 in Osteoarthritis and Cartilage: https://doi.org/10.1016/j.joca.2021.02.345.

\section{References}

1. Althubaiti A. Information bias in health research: definition, pitfalls, and adjustment methods. J Multidiscip Healthc. 2016;9:211-217. doi:10.2147/JMDH.S104807

2. Kriegsman DM, Penninx BW, van Eijk JT, Boeke AJ, Deeg DJ. Selfreports and general practitioner information on the presence of chronic diseases in community dwelling elderly. A study on the accuracy of patients' self-reports and on determinants of inaccuracy. $J$ Clin Epidemiol. 1996;49(12):1407-1417. doi:10.1016/S08954356(96)00274-0

3. Paganini-Hill A, Chao A. Accuracy of recall of hip fracture, heart attack, and cancer: a comparison of postal survey data and medical records. Am J Epidemiol. 1993;138(2):101-106. doi:10.1093/oxfordjournals.aje.a116832

4. Haapanen N, Miilunpalo S, Pasanen M, Oja P, Vuori I. Agreement between questionnaire data and medical records of chronic diseases in middle-aged and elderly Finnish men and women. Am J Epidemiol. 1997;145(8):762-769. doi:10.1093/aje/145.8.762

5. Zhang W, Doherty M, Peat G, et al. EULAR evidence-based recommendations for the diagnosis of knee osteoarthritis. Ann Rheum Dis. 2010;69(3):483-489. doi:10.1136/ard.2009.113100

6. National Institute for Health and Clinical Excellence (Great Britain). Osteoarthritis: care and management in adults. 2014.

7. Schuh-Renner A, Canham-Chervak M, Grier TL, Jones BH. Accuracy of self-reported injuries compared to medical record data. Musculoskelet Sci Pract. 2019;39:39-44. doi:10.1016/j. msksp.2018.11.007

8. Harlow SD, Linet MS. Agreement between questionnaire data and medical records: the evidence for accuracy of recall. Am J Epidemiol. 1989;129(2):233-248. doi:10.1093/oxfordjournals.aje.a115129

9. Bush TL, Miller SR, Golden AL, Hale WE. Self-report and medical record report agreement of selected medical conditions in the elderly. Am J Public Health. 1989;79(11):1554-1556. doi:10.2105/ AJPH.79.11.1554

10. Liu B, Sweetland S, Beral V, et al. Self-reported information on joint replacement and cholecystectomy agrees well with that in medical records. J Clin Epidemiol. 2007;60(11):1190-1194. doi:10.1016/j. jclinepi.2007.02.007

11. Sundboll J, Adelborg K, Munch T, et al. Positive predictive value of cardiovascular diagnoses in the Danish National Patient Registry: a validation study. BMJ Open. 2016;6(11):e012832. doi:10.1136/ bmjopen-2016-012832

12. Joensen AM, Jensen MK, Overvad K, et al. Predictive values of acute coronary syndrome discharge diagnoses differed in the Danish National Patient Registry. J Clin Epidemiol. 2009;62(2):188-194. doi:10.1016/j.jclinepi.2008.03.005

13. Thomsen RW, Lange P, Hellquist B, et al. Validity and underrecording of diagnosis of COPD in the Danish National Patient Registry. Respir Med. 2011;105(7):1063-1068. doi:10.1016/j. rmed.2011.01.012

14. Lasota AN, Overvad K, Eriksen HH, Tjonneland A, Schmidt EB, Gronholdt MM. Validity of peripheral arterial disease diagnoses in the Danish National Patient Registry. Eur J Vasc Endovasc Surg. 2017;53(5):679-685. doi:10.1016/j.ejvs.2016.12.031 
15. March LM, Schwarz JM, Carfrae BH, Bagge E. Clinical validation of self-reported osteoarthritis. Osteoarthritis Cartilage. 1998;6 (2):87-93. doi:10.1053/joca.1997.0098

16. Ratzlaff C, Koehoorn M, Cibere J, Kopec J. Clinical validation of an internet-based questionnaire for ascertaining hip and knee osteoarthritis. Osteoarthritis Cartilage. 2012;20(12):1568-1573. doi:10.1016/j.joca.2012.08.017

17. Short ME, Goetzel RZ, Pei X, et al. How accurate are self-reports? Analysis of self-reported health care utilization and absence when compared with administrative data. J Occup Environ Med. 2009;51 (7):786-796. doi:10.1097/JOM.0b013e3181a86671

18. Hamood R, Hamood H, Merhasin I, Keinan-Boker L. A feasibility study to assess the validity of administrative data sources and self-reported information of breast cancer survivors. Isr $J$ Health Policy Res. 2016;5:50. doi:10.1186/s13584-016-0111-6

19. Skou ST, Roos EM. Good life with osteoArthritis in Denmark (GLA: $\mathrm{d}^{\mathrm{TM}}$ ): evidence-based education and supervised neuromuscular exercise delivered by certified physiotherapists nationwide. BMC Musculoskelet Disord. 2017;18(1):72. doi:10.1186/s12891-017-1439-y

20. Vandenbroucke JP, von Elm E, Altman DG, et al. Strengthening the reporting of observational studies in epidemiology (STROBE): explanation and elaboration. Epidemiology. 2007;18(6):805-835. doi:10.1097/EDE.0b013e3181577511

21. The Danish Health Authority. Knee osteoarthritis - national clinical guidelines and referral guidelines. 2012.

22. Lynge E, Sandegaard JL, Rebolj M. The Danish national patient register. Scand J Public Health. 2011;39(7 Suppl):30-33. doi: $10.1177 / 1403494811401482$

23. Wallach Kildemoes H, Toft Sørensen H, Hallas J. The Danish national prescription registry. Scand J Public Health. 2011;39 (7 suppl):38-41. doi:10.1177/1403494810394717

24. Pedersen CB. The Danish civil registration system. Scand J Public Health. 2011;39(7_suppl):22-25. doi:10.1177/1403494810387965

25. Schmidt M, Schmidt SA, Sandegaard JL, Ehrenstein V, Pedersen L, Sorensen HT. The Danish National Patient Registry: a review of content, data quality, and research potential. Clin Epidemiol. 2015;7:449-490. doi:10.2147/CLEP.S91125

26. Thygesen SK, Christiansen CF, Christensen S, Lash TL, Sørensen HT. The predictive value of ICD-10 diagnostic coding used to assess Charlson comorbidity index conditions in the population-based Danish National Registry of Patients. BMC Med Res Methodol. 2011;11(1):83. doi:10.1186/1471-2288-11-83

27. Nielsen LH, Nørgaard BL, Tilsted HH, et al. The Western Denmark cardiac computed tomography registry: a review and validation study. Clin Epidemiol. 2015;7:53.

28. Landis JR, Koch GG. The measurement of observer agreement for categorical data. biometrics. 1977;33:159-174. doi:10.2307/2529310

29. StataCorp LP. Stata statistical software: release 16. College Station, TX; 2019.

30. Guldberg-Møller J, Cordtz RL, Kristensen LE, Dreyer L. Incidence and time trends of joint surgery in patients with psoriatic arthritis: a register-based time series and cohort study from Denmark. Ann Rheum Dis. 2019;78(11):1517-1523. doi:10.1136/annrheumdis-2019-215313

31. Hjelholt TJ, Edwards NM, Vesterager JD, Kristensen PK, Pedersen AB. The positive predictive value of hip fracture diagnoses and surgical procedure codes in the Danish multidisciplinary hip fracture registry and the Danish national patient registry. Clin Epidemiol. 2020;12:123-131. doi:10.2147/CLEP.S238722

32. Adelborg K, Sundboll J, Munch T, et al. Positive predictive value of cardiac examination, procedure and surgery codes in the Danish National Patient Registry: a population-based validation study. $B M J$ Open. 2016;6(12):e012817. doi:10.1136/bmjopen-2016-012817
33. Burcharth J, Liljekvist MS, Pommergaard H-C, Rosenberg J. Cumulative incidence and registry validation of groin hernia repair in a 34-year nationwide cohort. Dan Med J. 2016;63:A5284.

34. Parkinson L, Curryer C, Gibberd A, Cunich M, Byles JE. Good agreement between self-report and centralized hospitalizations data for arthritis-related surgeries. $J$ Clin Epidemiol. 2013;66 (10):1128-1134. doi:10.1016/j.jclinepi.2013.04.012

35. Hjertholm P, Flarup KR, Guldbrandt LM, Vedsted P. The completeness of chest X-ray procedure codes in the Danish National Patient Registry. Clin Epidemiol. 2017;9:151-156. doi:10.2147/CLEP. S124091

36. Haerskjold A, Henriksen L, Way S, et al. The Danish National Prescription Registry in studies of a biological pharmaceutical: palivizumab - validation against two external data sources. Clin Epidemiol. 2015;7:305-312. doi:10.2147/CLEP.S73355

37. Grimaldi-Bensouda L, Rossignol M, Aubrun E, Benichou J, Abenhaim L. Agreement between patients' self-report and physicians' prescriptions on nonsteroidal anti-inflammatory drugs and other drugs used in musculoskeletal disorders: the international Pharmacoepidemiologic General Research eXtension database. Pharmacoepidemiol Drug Saf. 2012;21(7):753-759. doi:10.1002/ pds. 3194

38. Pottegard A, Schmidt SAJ, Wallach-Kildemoes H, Sorensen HT, Hallas J, Schmidt M. Data resource profile: the Danish National Prescription Registry. Int J Epidemiol. 2017;46(3):798-798f.

39. Nielsen MW, Søndergaard B, Kjøller M, Hansen EH. Agreement between self-reported data on medicine use and prescription records vary according to method of analysis and therapeutic group. $J$ Clin Epidemiol. 2008;61(9):919-924. doi:10.1016/j.jclinepi.2007.10.021

40. Schneeweiss S, Avorn J. A review of uses of health care utilization databases for epidemiologic research on therapeutics. $J$ Clin Epidemiol. 2005;58(4):323-337. doi:10.1016/j.jclinepi.2004.10.012

41. Okura Y, Urban LH, Mahoney DW, Jacobsen SJ, Rodeheffer RJ. Agreement between self-report questionnaires and medical record data was substantial for diabetes, hypertension, myocardial infarction and stroke but not for heart failure. J Clin Epidemiol. 2004;57 (10):1096-1103. doi:10.1016/j.jclinepi.2004.04.005

42. Chun H, Kim IH, Min KD. Accuracy of self-reported hypertension, diabetes, and hypercholesterolemia: analysis of a representative sample of Korean older adults. Osong Public Health Res Perspect. 2016;7(2):108-115. doi:10.1016/j.phrp.2015.12.002

43. Linauskas A, Overvad K, Johansen MB, Stengaard-Pedersen K, de Thurah A. Positive predictive value of first-time rheumatoid arthritis diagnoses and their serological subtypes in the Danish National Patient Registry. Clin Epidemiol. 2018;10:1709-1720. doi:10.2147/ CLEP.S175406

44. Koller KR, Wilson AS, Asay ED, Metzger JS, Neal DE. Agreement between self-report and medical record prevalence of 16 chronic conditions in the Alaska EARTH Study. J Prim Care Community Health. 2014;5(3):160-165. doi:10.1177/2150131913517902

45. Gruneir A, Griffith LE, Fisher K, et al. Measuring multimorbidity series. An overlooked complexity-comparison of self-report vs. administrative data in community-living adults: paper 3. Measuring agreement across data sources and implications for estimating associations with health. $J$ Clin Epidemiol. 2020;124:173-182.

46. Susser SR, McCusker J, Belzile E. Comorbidity information in older patients at an emergency visit: self-report vs. administrative data had poor agreement but similar predictive validity. $J$ Clin Epidemiol. 2008;61(5):511-515. doi:10.1016/j.jclinepi.2007.07.009 


\section{Publish your work in this journal}

Clinical Epidemiology is an international, peer-reviewed, open access, online journal focusing on disease and drug epidemiology, identification of risk factors and screening procedures to develop optimal preventative initiatives and programs. Specific topics include: diagnosis, prognosis, treatment, screening, prevention, risk factor modification,

Submit your manuscript here: https://www.dovepress.com/clinical-epidemiology-journal systematic reviews, risk \& safety of medical interventions, epidemiology \& biostatistical methods, and evaluation of guidelines, translational medicine, health policies \& economic evaluations. The manuscript management system is completely online and includes a very quick and fair peer-review system, which is all easy to use. 